\title{
New insights into plastic instability in precipitation strengthened Al-Li alloys
}

\author{
Henry Ovri, Erica T. Lilleodden
}

Helmholtz-Zentrum Geesthacht, Institute of Materials Research, Materials Mechanics, MaxPlanck Straße 1, 21502 Geesthacht, Germany

\begin{abstract}
A mechanistic model that describes the microscopic mechanisms underlying plastic instability in precipitation strengthened Al-Li based alloy systems is proposed in this work. The model is based on experimental observations from high resolution nanoindentation tests and transmission electron microscopy (TEM) based methods, including in situ TEM tensile straining. These experiments show that dynamic strain aging (DSA), which is widely accepted as the underlying mechanism for plastic instability, cannot sufficiently account for the occurrence of plastic instability in Al-Li based alloy systems. It is proposed that an altogether different mechanism controls plastic instability, namely a diffusion-controlled pseudo-locking mechanism that accompanies order hardening. This mechanism does not require the concurrent operation of DSA by Li, which may be a nonviable mechanism given the low binding energy of Li to dislocation cores, for plastic instability to occur.
\end{abstract}

Keywords: Al-Li alloys, age hardening, plastic instability, order hardening, TEM

\section{Introduction}

A number of technologically important alloys, including steels, $\mathrm{Mg}, \mathrm{Cu}$ and Al-based alloys are known to exhibit discontinuous yielding during plastic deformation at critically low strain rates and over a range of temperatures [1-9]. This phenomenon, known as plastic instability or the Portevin-Le-Chaterlier (PLC) effect, has been extensively researched in order to understand the underlying microscopic mechanisms that govern it. Such understanding is 
critical to the design of alloys and process routes that mitigate undesirable effects such as reduction in ductility and formation of surface striations associated with the phenomenon [1, 9].

Several models, both phenomenological and theoretical, have been proposed to explain the origin of plastic instability in solution strengthened alloys [10-16]. Most of these models associate PLC-type plastic instability with dynamic strain aging (DSA), which refers to the solute aging of mobile dislocations temporarily trapped at localized obstacles such as forest dislocations. The increase in strength arising from this DSA process is claimed to govern negative strain rate sensitivity (nSRS), which is an anomalous behaviour that is manifested macroscopically as serrations in stress-strain curves [17]. Yet recent modelling efforts have shown that this DSA cannot independently lead to nSRS [18-20]. In view of this, Soare and Curtin [20] proposed a rate-dependent constitutive model for DSA in solution strengthened Al-Mg alloys that is not only predictive but also captures the physical mechanism associated with DSA. They show that solute aging of mobile and forest dislocations through cross-core diffusion must take place concurrently for nSRS to occur. Their model however suggests that since forest hardening is insignificant in precipitation strengthened alloys, plastic instability is not expected to occur in such materials unless a solute aging effect on the precipitate strengthening mechanism exists.

These theoretical models [18-20] question the widely accepted view that DSA by Li atoms alone governs plastic instability in precipitation strengthened Al-Li based alloys [21-25]. The plausibility of DSA by Li to activate nSRS in Al-Li alloys is further undermined by the rather weak binding energy of $\mathrm{Li}$ atoms to dislocation cores [26]. Others attribute the presence of instabilities in these alloys to the shearing of $\delta^{\prime}$ precipitates [27-30]. This second view is largely predicated on the fact that these precipitates are shearable and are often present in Al- 
Li based alloys that exhibit plastic instabilities. However, there is still no convincing model based on precipitate shearing that gives a clear mechanistic description of the origin of plastic instability in these alloys.

In this work, a number of techniques, including nanoindentation, micro-tensile testing, TEM and in situ TEM straining have been employed to critically examine the role of precipitates in mitigating or enhancing plastic instability and, more specifically, to identify the microscopic mechanism(s) that govern the phenomenon in Al-Li based alloys. The alloy used in this study, is AA2198, a new generation Al-Cu-Li-Mg-Zr alloy with desirable combination of specific strength and damage tolerance, making it suitable for aerospace structural applications. The attractive properties of this alloy are due to the presence of several metastable strengthening precipitates such as GP zones, $\delta^{\prime}\left(\mathrm{Al}_{3} \mathrm{Li}\right), \mathrm{T}_{1}\left(\mathrm{Al}_{2} \mathrm{CuLi}\right), \theta^{\prime}\left(\mathrm{Al}_{2} \mathrm{Cu}\right), \Omega\left(\mathrm{Al}_{2} \mathrm{Cu}\right)$ and $\mathrm{S}^{\prime}$ $\left(\mathrm{Al}_{2} \mathrm{CuMg}\right)$. These metastable phases are known to transform to equilibrium phases such as $\theta$ $\left(\mathrm{Al}_{2} \mathrm{Cu}\right), \mathrm{T}_{2}\left(\mathrm{Al}_{5} \mathrm{CuLi}_{3}\right)$ and $\mathrm{T}_{\mathrm{B}}\left(\mathrm{Al}_{7} \mathrm{Cu}_{4} \mathrm{Li}\right)$ after prolonged aging at elevated temperatures [3135], leading to a decrease in strength.

\section{Experimental procedure}

The AA2198 alloy used for this investigation was received in the T351 state, i.e. stretched to $2 \%$ elongation followed by naturally aging. This temper state hereafter referred to as NA temper, was used as starting material for subsequent heat treatment. Two different artificial aging treatments, $155^{\circ} \mathrm{C}$ for 14 hours and $370^{\circ} \mathrm{C}$ for 10 hours which produced peak (PA) and overaged (OA) tempers respectively were carried. The composition range of the AA2198 alloy in at. $\%$ is given in Table 1.

Table 1: Composition range of the major constituents of AA2198 given in at.\%.

\begin{tabular}{lccccc}
\hline Element: & $\mathrm{Li}$ & $\mathrm{Cu}$ & $\mathrm{Mg}$ & $\mathrm{Ag}$ & $\mathrm{Zr}$ \\
\hline Concentration (at.\%): & $3.11-4.27$ & $1.23-1.48$ & $0.29-0.89$ & $0.03-0.12$ & $0.01-0.05$ \\
\hline
\end{tabular}


Dog-bone shaped samples for microtensile testing with dimensions of $27 \times 3 \times 0.6 \mathrm{~mm}$ and gauge length of $11 \mathrm{~mm}$ were produced by wire-cut electro-discharge machining (W-EDM) from the short-transverse (S-T) direction. The microtensile tests were conducted at a strain rate of $5 \times 10^{-5} / \mathrm{s}$ in a Zwick universal testing station equipped with a non-contact multi-zone laser extensometer. The laser extensometer has a resolution of $1 \mu \mathrm{m}$ and thus facilitates the probing of the local strain distribution during straining in addition to the global strain response. The local and global strains were calculated from the displacements between markers placed $1 \mathrm{~mm}$ and $10 \mathrm{~mm}$ apart, respectively. Nanoindentation tests using two different loading profiles - constant strain rate $\left(5 \times 10^{-3} / \mathrm{s}\right)$ and strain rate jump protocols, were also carried out on these tempers using a Nanoindenter XP (Agilent, GmbH) equipped with a Berkovich indenter. The strain rate jump tests were performed at three different indentation strain rates ranging from 0.01 to $0.0005 \mathrm{~s}^{-1}$ using a base strain rate of $0.05 \mathrm{~s}^{-1}$. Details of the method used to conduct the nanoindentation strain rate jump test are given elsewhere [36].

$3 \mathrm{~mm}$ diameter discs for TEM analysis and rectangular shaped foils for the in situ TEM tensile straining tests prepared from the samples were electropolished in a twin-jet device with a solution of $67 \%$ methanol and $33 \%$ nitric acid at a temperature of $-20^{\circ} \mathrm{C}$ and current of $12 \mathrm{~V}$. A number of TEM lamellae were also produced by FIB milling in a Nova-200 dual-beam scanning electron microscope (SEM). The thickness of the FIB-milled lamellae was measured in the SEM prior to examination in the TEM. The TEM samples were examined in a JEOL 3010 microscope operated at 300KV and a Philips CM200 microscope operated at 200KV. The volume fraction of the $\delta^{\prime}$ phase in the NA and OA tempers was estimated with the relationship prescribed by Cahn and Nutting [37]. The reported average volume fraction is the average of at least three different micrographs taken from different areas of the sample. The mean particle size of the $\delta^{\prime}$ phase in each temper is the average radius of over 180 particles. In situ TEM tensile straining was also carried out inside the JEOL 3010 microscope using a 
displacement controlled single tilt, straining specimen holder. The microscope is equipped with a Gatan Orius CCD camera that allowed the recording of the experiments at a video rate of 33 frames per second.

\section{Microtensile and nanoindentation results}

Figure 1(a) shows the true stress, $\sigma_{t}$, vs. true strain, $\varepsilon_{t}$, response of the PA, NA and OA tempers from the microtensile experiments. Serrated flow indicative of plastic instability was observed in the OA temper but not in the PA and NA tempers. A small region of the plot is magnified in the insert in Figure 1(a) to more clearly reveal the serrations. An important observation is that the NA temper sustained a higher plastic strain than the OA temper even though the yield strength of the former is more than a factor of 2 higher than the latter. This underscores the detrimental effect of plastic instability on ductility

Figure 1(b) shows a plot of local and global strains vs. measurement time for the OA temper, the former being taken from the mid-section of the sample with a gage length of $1 \mathrm{~mm}$. The true stress response is also superimposed on the plot. Plastic instability, as captured by the stress and global strain response, was not very obvious in the early stage of plasticity. However, the local strain response, characterized by large stepwise increases in strain, reveals that the onset of the instability occurs shortly after yielding. This observation highlights the localized and microscopic nature of plastic instability.

In order to more carefully probe the microstructural influences on the serrated mechanical response and strain rate sensitivities, nanoindentation experiments were carried out; the highresolution load-displacement capabilities of nanoindentation makes it an effective tool for probing nanoscale perturbations such as plastic instability or strain localization [39]. Figure 2(a) shows the nanoindentation response of the different tempers. The response observed in the micro-tensile test, specifically the absence of plastic instability in all but the OA temper, 
was also observed in the load vs. displacement curve. As clearly shown in the magnified insert in the figure, the instability however manifested as characteristic steps with large bursts of displacement; the inherently load controlled nature of the nanoindentation tests precludes the formation of load drops during deformation [17,40]. Figure 2(b) presents a section of the nanoindentation curve obtained from the strain rate jump test. It shows the load vs. displacement response accompanying the change in nanoindentation strain rate from a very low strain rate, $0.0005 / \mathrm{s}$, to the base strain rate, 0.05/s. In the case of the PA temper, the change from the low to high strain rate regime was accompanied by an upward deviation from the loading path. In contrast, a downward deviation from the loading path was observed in the OA temper upon changing the strain rate from the low to the high regime. On the other hand, the loading path was continuous in the NA temper, except for the transient response that usually accompanies a sudden change in strain rate during deformation. These trends are more clearly shown in Figure 2(c), where the corresponding hardness response for the PA and OA tempers is shown. A significant increase in hardness accompanied the increase of the strain rate in the case of the PA temper, while in the case of the OA temper an increase in strain rate was followed by a drop in hardness, in agreement with the plot in Figure 2(b). The change in hardness of the NA temper (not shown) that followed the increase in strain rate was negligibly small. The behaviour of the PA and OA tempers in the strain rate jump test is indicative of positive and negative strain rate sensitivity, respectively, while that of the NA temper is characteristic of a strain rate in-sensitive material.

The hardness of the three tempers was observed to decrease with increasing indentation depth, a phenomenon commonly referred to as indentation size effect. The observed indentation size effect was found to be partly due to sink-in, a response associated with materials exhibiting strain hardening which leads to an overestimation of the contact area used in analysing nanoindentation data [41]. While the influence of sink-in can be corrected for by using a 
formulation of hardness that is independent of the contact area [41], such a correction did not fully remove the decrease in hardness with increasing displacement suggesting that there is an intrinsic indentation size effect present. This of course complicates the analysis of the strain rate sensitivity. However, since the load response, as given in Figure 2(b), is consistent with the trend observed in hardness, Figure 2(c), it can be argued that the effect of a change in strain rate on the hardness response is not influenced by the indentation size effect. In order to eliminate the influence of the size effect on the absolute value, the hardness at each strain rate was estimated from the intercept of a line drawn from the steady state hardness response at the given strain rate to the hardness axis.

The indentation strain rate sensitivity parameter, $m$, is plotted as function of variation in log of nanoindentation strain rate in Figure 3. The indentation rate sensitivity parameter, is analogous to the uniaxial strain rate sensitivity parameter and is defined as the ratio of the variation of the $\log$ of nanoindentation hardness $(\mathrm{H})$ and the associated variation in strain rate, $\dot{\varepsilon},[36]$ :

$$
m=\frac{\log \left(H_{1} / H_{2}\right)}{\log \left(\dot{\varepsilon}_{1} / \dot{\varepsilon}_{2}\right)}
$$

The SRS parameter, $m$, for the OA temper at all imposed variations of strain rate is in the negative domain of Figure 3. This clearly demonstrates that the observed displacement bursts in the load vs. displacement curve, Figure 2(a), for the OA temper are associated with plastic instability. In contrast, $m$ is approximately zero for the NA and positive for the PA temper, in agreement with the absence of plastic instability in these tempers.

\section{TEM analysis}

The distinctive mechanical response of the three investigated tempers is a direct result of the differences in interaction between dislocations and precipitates in these tempers. Although 
solution strengthening likely contributes to the $\sigma_{t},-\varepsilon_{t}$ response, it cannot exclusively account for the observed differences in work hardening rate, SRS and plastic instability. TEM characterization of the microstructural content in each temper was therefore performed in order to gain fully understanding of the influence of the precipitates on the underlying microscopic mechanisms. In the following, the main microstructural features of the three tempers are highlighted.

A high density of several phases including $\mathrm{T}_{1}, \Omega, \delta^{\prime}$ and $\mathrm{S}^{\prime}$ phase were present in the PA temper. This observation is consistent with the view that a combination of these phases leads to significantly high yield strength in this temper [43]. A dark field (DF) image showing one variants of $\mathrm{T}_{1}$ and the $\delta^{\prime}$ phase is shown in Figure $4(\mathrm{a}) . \mathrm{A}<112>_{\mathrm{Al}}$ SAD pattern showing spots arising from the $\Omega$ phase and streaks from the $S^{\prime}$ phase is superimposed in the micrograph $[43,45]$. The high density of precipitates in this temper and their associated strain fields completely overwhelmed the dislocation contrast, obviating the imaging of the dislocations structure in this temper.

The NA temper largely contained only $\delta^{\prime}$ precipitates, with average radius, $r$, of $10 \pm 5 \mathrm{~nm}$ and average volume fraction, $f, 0.004 \pm 6 \mathrm{e}-4$. Some of these precipitates had a donut shape configuration, which suggest that these must have nucleated on the $\beta^{\prime}$ phase [33]. A dark field (DF) image of the $\delta^{\prime} / \beta^{\prime}$ precipitates observed in this temper is shown in Figure 4(b). The typical dislocation structure found in the NA temper is shown in Figure 4(c). The dislocations are typically wavy, unevenly arranged, tangled and appear pinned by precipitates at several points along their line length. No evidence of dislocation pairs could be found.

Figure $4(\mathrm{~d})$ is a bright field $(\mathrm{BF})$ micrograph showing the key microstructural features observed within the grain interior in the $\mathrm{OA}$ temper. The $\mathrm{T}_{2}$ and $\mathrm{T}_{\mathrm{B}}$ precipitates are highlighted in this micrograph. These phases were also observed along the grain boundaries. 
$\mathrm{S}^{\prime}, \Omega$ and $\mathrm{T}_{1}$ phases were absent in this temper, an indication that these phases have either dissolved or transformed into equilibrium phases such as $T_{2}$ and $T_{B}$ phases. DF images made from $\mathrm{L}_{2}$ superlattice spots seen in SAD patterns obtained from this temper clearly revealed the presence $\delta^{\prime}$ phase, one such example is shown in Figure 4(e). The average radius, $r$ and average volume fraction, $f$ of the $\delta^{\prime}$ precipitates in this phase are $11 \pm 6 \mathrm{~nm}$ and $0.006 \pm 0.002$ respectively. The presence of $\delta^{\prime}$ phase in the OA temper is remarkable but consistent with observations made in multicomponent Al-Li alloy systems. It has been reported that $\delta^{\prime}$ phase is relatively stable in these alloy systems and may be present up to the overaged because of its coherency with the matrix [33]. Additionally, its coarsening rate has been shown to be

significantly reduced by the addition of small amount of Ag [46] and its precipitation on $\beta^{\prime}$ [47]. Figure 4(f) shows the typical dislocation configuration found in the overaged temper. The dislocations are mostly arranged in planar arrays and uniformly distributed on individual planes.

\section{In situ TEM}

In situ straining in the TEM was carried out in order to gain more insight into the dislocationprecipitation interactions. This test was employed to qualitatively assess the dislocation behaviour in the presence of the precipitates, since the in situ setup used obviates direct estimation of applied stress, strain rate and strain.

Still images taken from individual video frames that were recorded during the in situ TEM straining of the OA temper are shown in Figure 5. The corresponding video is included as supplementary material. The most remarkable observation made in this test is that the dislocations glided in pairs in almost all instances of observed dislocation activity. Each dislocation pair glided simultaneously until held up by obstacles along their path. Since the high stacking fault energy of $\mathrm{Al}$ obviates the formation of dislocation pairs with such wide 
spacing as observed in this test, it can be argued that the dislocation pairs are not Shockley partial dislocations, but rather pairs of perfect dislocations $[48,50]$.

In situ TEM straining was not carried out in the NA and PA tempers. Deductions about the dominant deformation mechanism in the NA temper were however made on the basis of the dislocation structure shown in Figure 4(c). Recall that the NA temper was strained 2\% prior to natural aging.

\section{Microscopic origin of plastic instability}

\subsection{Dynamic strain aging}

Although a quantitative characterization of the post-temper solute content in the matrix of the investigated tempers was not carried out, the microscopic analysis in the previous section show that the matrix solute content of NA, which contains only $\delta^{\prime}$ phase, is significantly higher than the solute content in the other tempers. The slightly higher volume fraction of $\delta^{\prime}$ phase in $\mathrm{OA}$ in comparison to NA, in addition to a high density of other precipitates, including Li bearing precipitates such as $T_{1}$ phase in PA and $T_{2}$ and $T_{B}$ phases in OA affirms this fact. In other words, if DSA by Li exclusively governs the occurrence of plastic instability in Al-Li based alloys, as suggested by several authors [21-25], then this phenomenon should ordinarily occur in the NA temper. Our analyses however show that this is not the case; the absence of plastic instability in the NA temper is clearly not associated with a deficiency of Li atoms. The decrease of $m$ to approximately 0 in the NA temper, Figure 2(b), may however indicate that strain aging of some sort occurs in NA but is insufficient to initiate nSRS and by extension plastic instability. This is consistent with the view that DSA cannot independently lead to plastic instability [18-20]. In the PA temper where the highest density of precipitates formed, $m$ is positive; the deficiency in solute atoms might obviate the occurrence of DSA. On the other hand, the absence of $T_{1}$ and other precipitates such $\Omega$ and $S^{\prime}$ in the OA temper 
partly indicates their dissolution into the matrix. The solute concentration of the OA temper will nevertheless be less than that of the NA temper. The occurrence of plastic instability in the OA temper, with a relatively lower Li matrix content than the NA temper, in which no instability is observed, and the unlikelihood of dislocation pinning by Li, a tendency attributed to the weak binding energy of Li to dislocation cores [26], strongly suggest that DSA by Li does not govern plastic instability in AA2198. DSA by Mg, which is a well-known dynamic ageing species, is also unlikely since the nominal concentration of $\mathrm{Mg}$ in the investigated alloy is less than the experimentally determined critical concentration of $\mathrm{Mg}$ for plastic instability [49]. Similarly, it is highly unlike that forest aging can independently govern plastic instability since its rate sensitivity is known to be very small [20].

\subsection{Precipitate shearing}

As mentioned earlier, a number of authors have argued that plastic instability can be independently caused by the shearing of $\delta^{\prime}$ phase in Al-Li alloys [27-30]. A major setback of models proposed by these authors is that they cannot account for the nSRS that accompanies plastic instability. For instance, Pink and co-workers [27] propose that the collective glide of dislocations piled up at the matrix- $\delta^{\prime}$ interface through the $\delta^{\prime}$ precipitate would lead to plastic instability. Apart from the fact that this mechanism does not account for nSRS, the absence dislocation pile ups at the $\delta^{\prime}$ precipitates present in the OA temper (cf. Figure 4f) where plastic instability occurred indicate that such a mechanism does not occur in these alloy and is therefore unlikely the origin of the instabilities. Brechet and Estrin [30], based on their theoretical model proposed, that the shearing of precipitates accompanied by their dissolution and subsequent rapid re-precipitation during deformation can independently lead to nSRS. The time and temperature requirements for the complete dissolution and re-precipitation of $\delta^{\prime}$ 
after shearing however preclude the operation of such a mechanism at ambient temperatures $[25,27]$

The TEM analyses done here clearly show that although $\delta^{\prime}$ phase is present in all three investigated tempers, the mechanical response in terms of the occurrence of plastic instability and the dislocation structure in these tempers are significantly different. Specifically, slip is wavy and heterogeneous in NA while it is planar and homogenous in OA. Since strain localization, which is one of the negative effects of plastic instability, is associated with planar and homogeneous slip $[50,51]$, it is surmisable that the occurrence of plastic instability would be strongly influenced by the predominant strengthening mechanism.

The planar nature of slip in the OA temper, Figure 4(f), in addition to the simultaneous glide of dislocation pairs observed in the in situ TEM tests, Figure 5, indicate that the dominant strengthening mechanism in this temper is order hardening. This observation is consistent with the widely accepted view that slip in Al-Li alloys containing $\delta^{\prime}$ phase, which is a coherent and ordered phase, occurs by the glide of pairs of perfect dislocations. It is well established that the leading dislocations of the pairs destroys the order and creates an antiphase boundary (APB) within the precipitates upon shearing them while the trailing dislocations, moving in concert with the leading dislocation restores order in the precipitates. The energy of the APB represents the resistance that must be overcome by the matrix dislocations for slip to occur. Since the area of the antiphase boundary decreases with shearing, further deformation is favoured in the already sheared planes. Slip is therefore localized and planar in alloys where this mechanism is dominant [52-54]. Under the ideal conditions, i.e. when the APB formed by the leading dislocation $\left(D_{1}\right)$ of the pair is perfectly restored by the trailing dislocation $\left(\mathrm{D}_{2}\right)$, the force equilibrium for the dislocation pair, $\mathrm{D}_{1}$ and $D_{2}$, at the critical configuration (Figure 6) is given in equations (2) and (3) [50]: 


$$
\begin{aligned}
& \mathrm{D}_{1}: \tau b+\left(G b^{2} / 2 \pi(1-v) \Lambda\right)-\gamma_{a p b} d_{1} / l_{1}=0 \\
& \mathrm{D}_{2}: \tau b-\left(G b^{2} / 2 \pi(1-v) \Lambda\right)+\gamma_{a p b} d_{2} / l_{2}=0
\end{aligned}
$$

where $\tau$ is the applied shear stress, $G$ is the shear modulus, $b$ is the Burgers vector of the dislocations, $d_{i}$ is the average length of $\mathrm{D}_{\mathrm{i}}$ lying in a precipitate, $l_{\mathrm{i}}$ is the mean distance between the precipitates sampled by $D_{i}, \Lambda$ is the separation distance between the dislocation pair, $v$ is the Poisson's ratio of the matrix and $\gamma_{a p b}$ is the energy of the antiphase boundary per unit area in the $\delta^{\prime}$ phase. Summation of equations (2) and (3) and rearranging terms leads to the elimination of the middle term, i.e. the force of interaction between the dislocations, and results in equation (4):

$$
\tau^{O H}=\gamma_{a p b} \frac{d_{1}}{2 b l_{1}}-\gamma_{a p b} \frac{d_{2}}{2 b l_{2}}
$$

where $\tau^{O H}$ is the theoretical critical resolved shear stress predicted by order hardening. For an alloy system dominated by order hardening, $\tau^{O H} \approx \tau$. Following the work of Argon [50], equation (4) can be rewritten as:

$$
\tau^{O H}=\frac{\gamma_{a p b} f^{\frac{1}{2}}}{2 b}\left[1.731\left(\frac{\pi \gamma_{a p b} r_{o}}{4 G b^{2}}\right)^{\frac{1}{2}}-f^{\frac{1}{2}}\right]
$$

where $r_{o}$ is the average precipitate radius and $f$ the volume fraction of the precipitates. The theoretical yield strength derived from the order hardening mechanism, $\sigma_{y}^{O H}$, where $\sigma_{y}^{O H}=$ $M * \tau^{O H}$ was found to be $\approx 71 \mathrm{MPa}$ for OA and $\sigma_{y}^{O H} \approx 55 \mathrm{MPa}$ for NA, using the Taylor factor, $M=2.95$ [55], $G=30 \mathrm{GNm}^{-2}, b=0.2864 \mathrm{~nm}, \gamma_{a p b}=0.15 \mathrm{Jm}^{-2}$ [52] and values of $r_{o}$ and $f$ derived from the TEM analysis done in this work (cf. section 4). The experimental yield strength, $\sigma_{y}^{\text {exp }}$, for OA and NA is $133 \mathrm{MPa}$ and $310 \mathrm{MPa}$ respectively. The fairly high value of $\sigma_{y}^{O H}\left(=M * \tau^{O H}\right)$ obtained for the OA temper additionally supports the view that order 
hardening is dominant in OA but not in the NA temper. The difference between $\sigma_{y}^{e x p}$ and $\sigma_{y}^{O H}$ for the OA can be attributed to contributions from solute atoms, matrix dislocations and the equilibrium precipitates. The contributions of equilibrium precipitates such as $T_{2}$ and $T_{B}$ to strength are known to be negligibly small [56], as such their presence will not alter the slip configuration in OA. On the other hand, the wavy and heterogeneous nature of slip in the NA temper suggests that a mechanism other than order hardening is prevalent. Recent reports associate the high yield strength in the NA temper with the presence of $\mathrm{Cu}$-rich clusters [38].

\subsection{Proposed mechanism of plastic instability}

It is apparent from the preceding analysis that dynamic aging of both mobile and forest dislocations do not govern plastic instability in the AA2198. The analysis rather indicates that an alternate mechanism is responsible for, for plastic instability in this alloy. Our results strongly suggest that this mechanism is order hardening; pairwise dislocation activity, a major fingerprint of order hardening in these alloy systems, was clearly observed in the in situ TEM straining experiment (Figure 5). We propose that the nSRS associated with plastic instability is induced by a diffusional reordering in the precipitates, resulting in a pseudo-locking mechanism analogous to that proposed by Morris [57] and Cuniberti [58] for discontinuous yield point phenomena in bulk long range-ordered alloys. In those models, the diffusional rearrangement of the APBs and its resultant decrease in energy in order-disorder alloys is proposed to account for the observed increase in the dissociation distance between the super partial dislocations. Now such a diffusional rearrangement of the APB in the $\delta^{\prime}$ precipitates is proposed as the explanation for the plastic instability, and its associated nSRS, in the OA temper.

The first key point to note in the development of the pseudo-locking mechanism is the realization that the assumption that precipitation hardening is rate independent applies mostly 
to the peak- or overaged states where the ratio of the obstacle peak resistance force $(\hat{k})$ and line tension of the dislocation $(2 \xi)$ is greater than one. The glide of dislocations through an array of precipitates can actually be rate dependent in the underaged states where $\hat{k} / 2 \xi<1$ [50][59]. Argon [50] contends that the effective (applied) stress on the dislocation upon entering the precipitate is resisted by a force, $k$, which is slightly less than $\hat{k}$ but is at a stable equilibrium position. It is further argued that the energy barrier between this initial equilibrium position and a so-called saddle-point position, which is almost at the exit point of the dislocation from the precipitate, is overcome by thermal activation. A simplified form of the theoretical CRSS predicted by order hardening for such a thermally assisted shearing process, $\tau^{O H}(T, \dot{\gamma})$, can be written as [50]:

$$
\tau^{O H}(T, \dot{\gamma})=\tau^{O H}\left[1-\left(\frac{T k \ln \left(\dot{\gamma}^{*} / \dot{\gamma}\right)}{\Delta G_{O}{ }^{*}}\right)^{\frac{1}{q}}\right]^{\frac{1}{p}}
$$

where $T$ is the temperature, $\dot{\gamma}$ is the shear strain rate, respectively, $p$ and $q$ are constants in the range: $0.5-1.0$ and $1.0-2.0$ respectively, $\Delta G_{o}{ }^{*}$ is a reference Gibbs free energy of thermal activation for the dislocation to move from the initial equilibrium position to the saddle-point. $\Delta G_{o}{ }^{*}$ is usually taken at $T=0 \mathrm{~K}$ as a first approximation. $k$ is the Boltzmann constant. The term $\dot{\gamma}^{*}$ can be expressed as:

$$
\dot{\gamma}^{*}=b \rho_{m} \lambda v_{G}
$$

where $\rho_{m}$ is the mobile dislocation density, $\lambda$ is the Friedel spacing and $v_{G}$ is the attempt frequency of a dislocation overcoming a thermally penetrable obstacle. Although the difference in strength arising from the thermal component is expected to be very small, it may nevertheless provide sufficient waiting time for the diffusion mechanism proposed now to occur. 
As previously mentioned, a major characteristic of the order hardening mechanism is that the ordered precipitates form APBs in their active glide planes when they are sheared. The APB will be highly energetically unstable because of the many like bonds across it. There may therefore be sufficient time at low strain rates for thermal activation to modify this unstable interface by atomic rearrangement, i.e., reducing the number of like bonds across the APB. This atomic rearrangement will partially relax the APB, and in turn will reduce the attractive pull of the APB on the trailing dislocation $\left(\mathrm{D}_{2}\right) \cdot \tau^{\mathrm{OH}}$ will thus become rate dependent since the second term in equation (4) will decrease with time. Assuming that the energy of the relaxed APBs ahead of the trailing dislocation is $\gamma_{a p b}^{\prime}$, equation (4) can be re-written as:

$$
\tau^{O H}=\gamma_{a p b} \frac{d_{1}}{2 b l_{1}}-\gamma_{a p b}^{\prime} \frac{d_{2}}{2 b l_{2}}
$$

Since $\gamma_{a p b}^{\prime}$ is diffusion rate controlled, it can be related to $\gamma_{a p b}$ by an Arrhenius type equation of the form:

$$
\gamma_{a p b}^{\prime}=\gamma_{a p b} * e^{\left(-K t_{w}\right)}
$$

where $K$ is an exponential factor and $t_{w}$ is the waiting time during which the atomic rearrangements occurs when a dislocation is pinned in the precipitate; $t_{w}=0$ is associated with the time at which the lead dislocation enters the precipitate and the APB is initiated. Following the usual approach in DSA models $[10,18], t_{w}$ can be defined in terms of the strain rate as: $t_{w}=\Omega / \dot{\gamma}$, where $\Omega$ in our case will be related to the precipitate size. Incorporation of equation (8) into equation (6) after appropriate substitution for $t_{w}$ and $\gamma^{\prime}{ }_{a p b}$ leads to:

$$
\tau^{O H}(T, \dot{\gamma})=\left[\gamma_{a p b}\left(\frac{d_{1}}{2 b l_{1}}-e^{-\left(\frac{K \Omega}{\dot{\gamma}}\right)} \frac{d_{2}}{2 b l_{2}}\right)\right]\left[1-\left(\frac{T k \ln \left(\dot{\gamma}^{*} / \dot{\gamma}\right)}{\Delta G_{o}{ }^{*}}\right)^{\frac{1}{q}}\right]^{\frac{1}{p}}
$$

Equation (10) is the theoretical CRSS predicted by order hardening for a thermally assisted shearing process combined with the effect of a diffusional rearrangement of the APB. 
Although the exact form of the terms $K$ and $\Omega$ in equation (10) is not yet clear, it is apparent on inspection that $\tau^{O H}(T, \dot{\gamma})$ increases with decreasing strain rate, $\dot{\gamma}$. In other words, higher shear stresses are required at low strain rates where atomic rearrangement occurs relative to high strain rates where these rearrangements will not occur because of in-sufficient time for diffusion.

The mechanism of locking is such that at very low strain rate, atomic rearrangement will occur in precipitates sheared by $D_{1}$, while $D_{2}$ becomes locked because the APB ahead of it has been partly reordered. This requires an increase in applied shear stress, $\Delta \tau$, for $\mathrm{D}_{2}$ to glide. $D_{1}$ will also be locked because $D_{2}$ provides part of the energy required by $D_{1}$ at the current applied stress to continue deformation; the extra "push" supplied by the Peach-Köhler force decreases with increases separation distance between the dislocations. A pseudo-locking situation is therefore created under the condition of coupled dislocation glide. This APB locking effectively gives rise to a lowering of the SRS since an increase in $\tau$ will be required for deformation at low strain rates.

Figure (7) schematically illustrates both (a) edge-on and (b) in-plane views of the mechanism just described, in terms of the time dependent reordering of the slip plane from the perfect APB to a more re-ordered slip plane. At high strain rate the ordering hardening mechanism proceeds normally, with no rearrangement of the slip plane composition. With decreasing strain rate, diffusion is allowed to bring the entire precipitate to a more uniform composition, thus lowering the APB energy ahead of the trailing dislocations.

\section{Discussion}

The mechanistic description of the origin of plastic instability in AA2198 given above effectively explains the occurrence of plastic instability in other Al-Li alloys systems. It can be argued that plastic instability does not occur in the NA temper of the AA2198 alloy studied 
here, in spite of sufficient amount of $\mathrm{Li}$ in its matrix, because strengthening in this temper is not governed by order hardening. The influence of the pseudo-locking mechanism is therefore insignificant, consequently plastic instability is inhibited. As observed in this work and consistent with other reports [31-33], subsequent aging to the PA temper leads to the precipitation of more potent strengthening precipitates such as $\mathrm{S}^{\prime}, \Omega$ and $\mathrm{T}_{1}$ phases. The precipitation of these additionally reduces the contribution of $\delta^{\prime}$ phase in strengthening. Under these conditions, the diffusion-controlled pseudo locking mechanism and by extension plastic instability will be suppressed. The dissolution of potent metastable phases such $\mathrm{Cu}$ clusters, $\mathrm{S}^{\prime}, \Omega$ and $\mathrm{T}_{1}$ and the formation of equilibrium phases as such $\mathrm{T}_{2}$ and $\mathrm{T}_{\mathrm{B}}$ at high aging temperatures/time effectively increases the contribution of the $\delta^{\prime}$ phase, i.e. order hardening to the total CRSS in the OA temper. With order hardening dominating strengthening in this temper, the pseudo-locking mechanism becomes more active at low strain rates and thus provides the nSRS for plastic instability to occur.

A critical review of the literature shows that in binary Al-Li systems, plastic instability occurs from the quenched state until the peak aged state, where the instability has be found to disappear $[21,25,28,60]$. This observation explains why several authors [21-25] argue for DSA as the origin of plastic instability in Al-Li alloys. Proponents of this view associate the disappearance of instabilities in these alloys to the depletion of Li from the matrix as a result of the precipitation of $\delta^{\prime}\left(\mathrm{Al}_{3} \mathrm{Li}\right)$ phase. The experimental evidence provided in this work however shows that DSA acting alone is not sufficient to cause plastic instability. Since $\delta^{\prime}$ phase is known to form rapidly at room temperature upon quenching from the solution treated state [62], it can be argued that order hardening already operates from the early stages of aging in the binary Al-Li systems and governs strengthening in binary Al-Li alloys. Conditions for plastic instability to occur, i.e., DSA and order hardening, are therefore always 
present in these alloys up to the peak aged state. At the peak aged state, DSA and, by extension, plastic instability may be inhibited as a result of a possible breakdown of the order hardening mechanism. It is argued that at the peak aged state in binary Al-Li alloys, the precipitate radius reaches a limiting value where precipitate shearing tends to give way to looping [61]. Order hardening will be prevented from occurring under such conditions.

In quaternary and commercial Al-Li based alloys, the instability behaviour is quite varied and largely depends on the composition of the alloy and its thermomechanical treatment. Nonetheless, the disappearance of plastic instability in these alloys usually occurs in the underaged states $[22,38,63]$ and can be attributed to the precipitation of more potent strengthening precipitates such as $T_{1}$ and $S^{\prime}$. When strengthening from these phases become dominant, the order hardening mechanism and the pseudo-locking mechanism described above will be suppressed. It can be argued that there will still be sufficient amount of Li in the matrix in the underaged states of these alloys to facilitate DSA but the suppression of order hardening hinders the manifestation of the plastic instability.

While the pseudo-locking mechanism proposed herein to account for the nSRS strongly hinges on the energetic driving forces for two distinct processes, namely the diffusional rearrangement of atoms within the $\delta^{\prime}$ precipitates and the energy difference between the perfect $\mathrm{APB}$ and that after diffusional rearrangement, i.e. the diffuse APB, these aspects cannot be directly experimentally addressed; ab initio calculations, which are not yet available within the literature for these alloy systems, are needed to fully establish the viability of the diffusional rearrangement and the magnitude of the energy difference that accompanies it. However, the occurrence of rapid and significant APB relaxation at homologous temperatures, which are comparable with that of the experiments carried out within the 
present work, has indeed been observed in bulk, long-range ordered alloy systems such as $\mathrm{Cu}$ $\mathrm{Zn}-\mathrm{Al}, \mathrm{Al}_{5} \mathrm{Ti}_{2} \mathrm{Fe}, \mathrm{Al}_{5} \mathrm{Ti}_{2} \mathrm{Mn}$ and $\mathrm{Ni}_{3} \mathrm{Fe}[57,58]$.

\section{Conclusion}

It has been shown, on the basis of detailed experimental investigations of instability behaviour of AA2198, that dynamic strain aging (DSA) cannot sufficiently account for the occurrence of plastic instability in Al-Li based systems as is often assumed [21-25]. This observation is consistent with conclusions made recently for solution strengthened alloys that exhibit plastic instability. While a higher concentration of solute atoms - including $\mathrm{Li}$ - was present in the naturally aged temper (NA) of the AA2198 in comparison with the overaged temper (OA), plastic instability was only observed in the latter. It is proposed that a diffusion-controlled mechanism which involves the operation of a pseudo-locking mechanism that accompanies order hardening at low strain rates initiates negative strain rate sensitivity (nSRS) which subsequently leads to plastic instability in AA2198. This model is supported by observations of the diffusional rearrangement of the APBs and associated reduction in APB energy in order-disorder alloys [57-58]. Finally, it was also shown that the model adequately rationalizes the occurrence of plastic instability in both binary and other multi-component AlLi based alloys.

\section{Supplementary material:}

https://www.dropbox.com/s/ifpsg94piew37yz/Overaged\%20temper.mp4?dl=0

\section{Acknowledgements}

We acknowledge the scientific support of Josh Kasher, Qian Yu and Andy Minor from the National Centre for Electron Microscopy (NCEM) at Lawrence Berkeley Laboratory, which is supported by the U.S. Department of Energy under Contract \# DE-AC02-05CH11231. We are also indebted to Prof. William Curtin of EPFL for insightful discussions. 


\section{References}

[1] Picu RC, Vincze G, Ozturk F, Gracio JJ, Barlat F, Maniatty, AM. Mater Sci Eng A $2005 ; 390: 334$.

[2] Thevenet D, Milha-Touati M, Zeghloul A. Mater Sci Eng A 1999; 266:175.

[3] Klose FB, Weidenmüller J, Ziegenbein A, Hähner P, Neuhäuser H. Phil Mag A 2004; 84(3-5):467.

[4] Qiu W, Han E, Liu L. J Mater Sci Tech 2009; 25(4):441.

[5] Corby C, Cáceres CH, Lukác P. Mater Sci Eng A 2004; 387:22.

[6] Canadinc D, Efstathiou C, Sehitoglu H. Scr Mater 2008; 59(10):1101.

[7] Hong S-G, Lee S-B. J Nuclear Mater 2005: 340: 307.

[8] Shen YZ, Oh KH, Lee DN. Mater Sci Eng A 2006; 435:343.

[9] Yilmaz A. Sci Technol Adv Mater 2011; 12: 063001.

[10] Picu RC. Acta Mater 2004; 52:3447-3458

[11] Dierke H, Krawehl F, Graff S, Forest S, Sachl J. Neuhäuser H. Comp Mater Sci 2007; 39(1):106.

[12] Mulford RA, Kocks UF. Acta Metall 1979; 27:1125

[13] Estrin Y, Kubin LP. Mater Sci Eng A 1991; 137:125-.

[14] Kubin LP, Estrin Y. Phys Stat Sol B 1992; 172:173.

[15] Schoeck G. Acta Metall 1984; 32(8):1229.

[16] Franklin SV, Mertens F, Marder M. Phys Rev E 2000; 62(6):8195.

[17] Rizzi E, Hähner P. Intl J Plast 2004; 20:121.

[18] Hähner P. Material Science and Engineering A 1996; 207:208.

[19] Soare MA, Curtin WA. Acta Mater 2008; 56:4091.

[20] Soare MA, Curtin WA. Acta Mater 2008; 56:4046.

[21] Kumar S, Król J, Pink E. Scr Mater 1996; 35(6):775. 
[22] Gregson PJ, McDarmaid DS, Hunt E. Mater Sci Tech 1988; 4:713.

[23] Cieslar M, Vostrý P, Stulíková I. Phys Stat Sol 1996; 157:217.

[24] Kubin LP. Styczynski A, Estrin Y. Scr Mater 1992; 26:1423-.

[25] Chmelík F. Pink E, Król J, Balík J, Pešička J, Lukáč. Acta Mater 1998; 46(12): 4435.

[26] Evans JT. Scr Metall 1987; 21:1435.

[27] Pink E, Kumar S, Baohui T. Mater Sci and Eng A 2000; 280:17.

[28] Behnood N, Evans JT. Acta Metall 1989; 37(2):687.

[29] Kumar S, Pink E. Scr Metall Mater 1995; 32(5):749.

[30] Brechet Y, Estrin Y. Scr Metall Mater 1994; 31(5):185.

[31] Alexopoulos ND, Migklis E, Stylianos A, Myriounis DP. Int J Fatigue 2013; 56:95.

[32] Donnadieu P, Shao Y, De Geuser F, Botton GA, Lazar S, Cheynet M, De Boissieu M, Deschamps A. Acta Mater 2011; 59:462.

[33] Wang SC, Starink MJ. Int Mater Rev 2005; 50(4):193.

[34] Lee YS. J Mater Sci Lett 1998; 17:1161.

[35] Chen PS, Bhat BN. NASA/TM 2002:211548

[36] Maier V, Durst K, Mueller J, Backes B, Höppel HW, Göken M. J Mater Res 2011; 26(11):1421.

[37] Cahn JW, Nutting J. Trans Metall Soc AIME, 1959; 215:526.

[38] Deschamps A, Decreus B, De Geuser F, Dorin T, Weyland M. Acta Mater 2013; 61:4010.

[39] Schuh CA. Mater Today, 2006, 9(5): 32.

[40] Chinh NQ, Gubicza J, Kovács Z, Lendvai J. J Mater Res 2004; 19(1): 31.

[41] Oliver WC, Pharr GM. J Mater Res 1992; 7(6): 3.

[42] Lucas BN, Oliver WC. Metall Mater Trans A 1999; 30:601.

[43] Rioja RJ, Liu J. Met Mater Trans A 2012; 43:3325. 
[44] Ringer SP, Muddle BC, Polmear IJ. Metall Mater Trans A 1995; 26:1659.

[45] Pickens JR, Kumar KS, Brown SA, Gayle FW. NASA/ STI 1991; 19910015091: p60.

[46] Lee BC, Park JK. Acta mater 1998; 46(12):4181.

[47] Radmilovic V, Tolley A, Marquis EA, Rossell MD, Lee Z, Dahmen U. Scr Mater 2008; 58:529.

[48] Rosner H, Liu W, Nembach E. Phil Mag A 1999; 79(12):2935.

[49] Chinh NQ, Csikor F, Kovács Z, Lendvai J. J Mater Res 2000; 15(5): 1037.

[50] Argon AS. Strengthening mechanisms in crystal plasticity. Oxford Uni press, 2008.

[51] Gerold V, Karnthaler HP. Acta Metall 1989; 37(8):2177-2183.

[52] Huang JC, Ardell AJ. Mater Sci Engrg A 1988; 104:149.

[53] Schlesier C, Nembach E. Acta Metall Mater 1995; 43(11): 3983.

[54] Noble B, Harris SJ and Dinsdale K. Metall Sci 1982; 16: 425.

[55] Starink MJ, Wang P, Sinclair I, Gregson. Acta Mater 1999; 47(14):3855.

[56] Shercliff HR, Ashby MF. Acta Metall Mater 1990; 38(10):1789.

[57] Morris DG, Besag FMC, Smallman RE. Acta Metall 1974; 22:801.

[58] Cuniberti A, Niewczas M. Scri Mater 2001; 45:853.

[59] Nix WD, Menezes RA. Annu Rev Mater Sci 1971; 1:313.

[60] Sun DL, Yang DZ, Lei TQ. Mater Chem Phys 1990; 25: 307.

[61] Ardell AJ. Metall Trans A 1985; 16: 2131.

[62] Lendvai J, Wunderlich W, Gudladt HJ. Phil Mag A 1993; 67(1):99.

[63] Wert JA, Wycliffe PA. Scri Metall 1985; 19:463-466. 


\section{Figure Captions}

Figure 1: (a) True stress vs true strain of different tempers: peak aged (PA) in purple, naturally aged (NA) in blue and overaged (OA) in red. The serrations in the OA temper are magnified in the insert. (b) The local (in pink) and global (in brown) strain responses plotted as a function of time. The corresponding stress response is also shown in the plot.

Figure 2: (a) Load-displacement curve of the three tempers. The magnified insert shows distinct strain bursts associated with plastic instability. (b) A section of the load vs. displacement response from the strain rate jump tests. The associated imposed strain rate (black line) is included in the plot. The broken line is a guide for the eyes. The corresponding hardness response for the PA and OA tempers is shown in (c). Colour codes are as previously defined.

Figure 3: Strain rate sensitivity, $\mathrm{m}$, as a function of the change in strain rate: purple squares = peak aged $(\mathrm{PA})$, blue triangles $=$ naturally aged $(\mathrm{NA})$, red circles $=$ overaged $(\mathrm{OA})$.

Figure 4: (a) A DF image of the PA temper showing one variant of the $\mathrm{T}_{1}$ and $\delta^{\prime}$ phase. The insert is a $<112>\mathrm{Al}$ zone axis $\mathrm{SAD}$ pattern showing spots arising from $\delta^{\prime}, \Omega$ and $\mathrm{T}_{1}$ phases. Streaks arising from $S^{\prime}$ can be seen along the $<420>$ matrix direction. (b) A DF image showing $\delta^{\prime}$ precipitates in the NA temper. (c) A typical dislocation structure in NA temper. (d) BF image showing the key precipitates present in the OA temper. (e) A DF image showing $\delta^{\prime}$ precipitates in the OA temper. (f) A typical dislocation structure in the OA temper.

Figure 5: Series of still images taken from video frames recorded during in situ TEM tensile straining of the overaged sample. The black arrows show dislocations that glide concurrently.

Figure 6: Critical configuration of a dislocation pair cutting through a group of ordered coherent $\delta^{\prime}$ precipitates. The shaded spheres represent precipitates with perfect APBs while the open spheres represent ordered precipitates. Spheres with both open and shaded areas represent precipitates with partial APBs. $d_{i}$ is the average length of the dislocation, $D_{i}$ lying in a precipitate, $l_{\mathrm{i}}$ is the mean distance between the precipitates sampled by $\mathrm{D}_{\mathrm{i}}$ and $\Lambda$ is the average distance between $\mathrm{D}_{1}$ and $\mathrm{D}_{2}$.

Figure 7: Simplified illustration of (a) an edge-on view of the mechanism proposed here-in. At high strain rates the passage of the of leading dislocation, $D_{1}$, through the $\delta^{\prime}$ phase leaves an anti-phase boundary (APB) in its wake (i.e., ii), while the passage of the trailing dislocation, $\mathrm{D}_{2}$, recovers the perfect ordering of the precipitate (i.e., iii). At slow strain rates, a diffusion-controlled re-ordering of the APB between steps (ii) and (iii) leads to a higher critical stress for the second dislocation to pass through the precipitate. (b) an in-plane view of the slip plane through the $\delta^{\prime}$ phase, showing the perfectly ordered state (i), the full APB (ii), the (relaxed) APB after a time, $t$, prior to the passage of $\mathrm{D}_{2}$ (iii), the partially re-ordered slip plane formed after the passage of $\mathrm{D}_{2}$ (iv) and the perfectly re-ordered slip plane. 


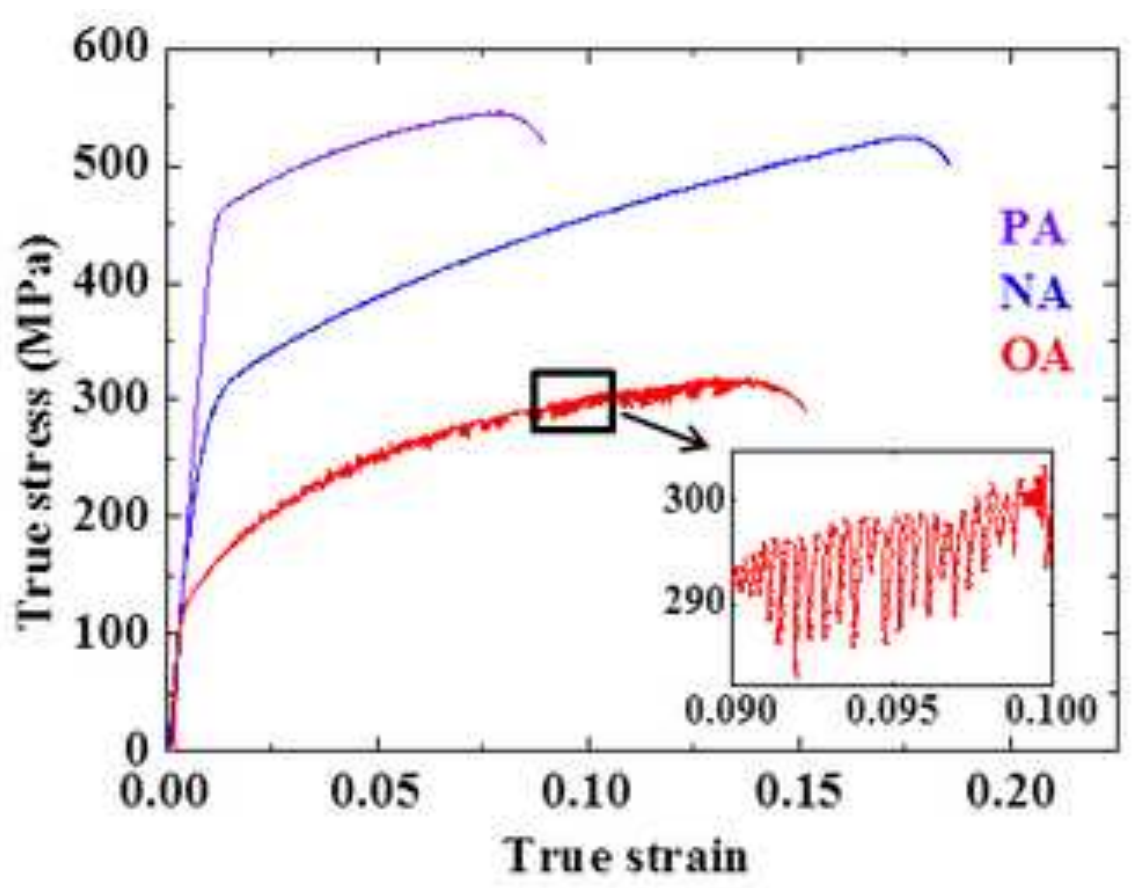

(a)

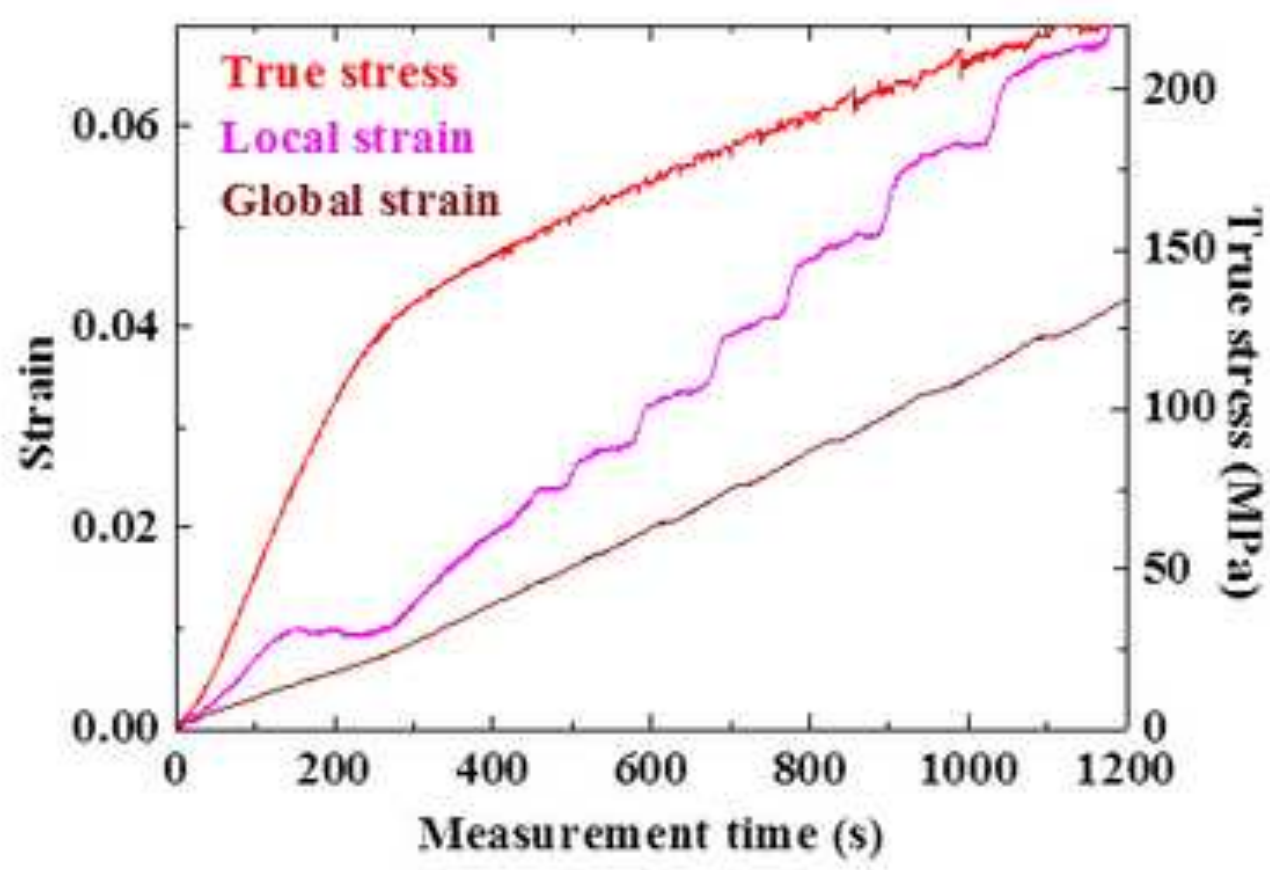

(b) 


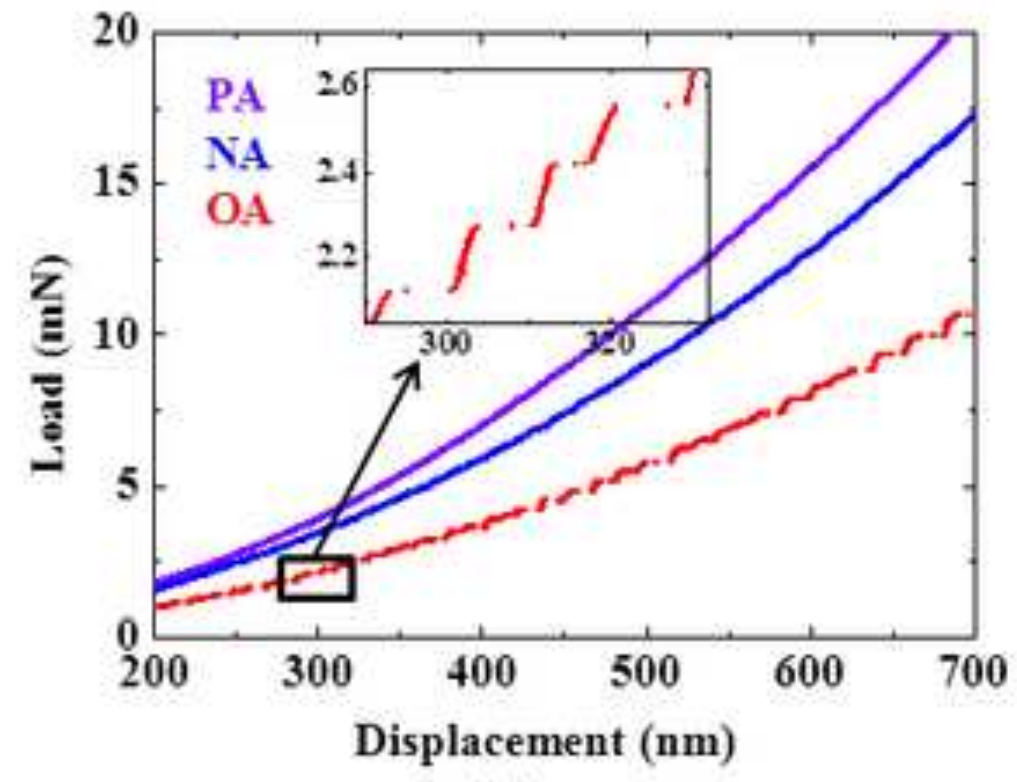

(a)

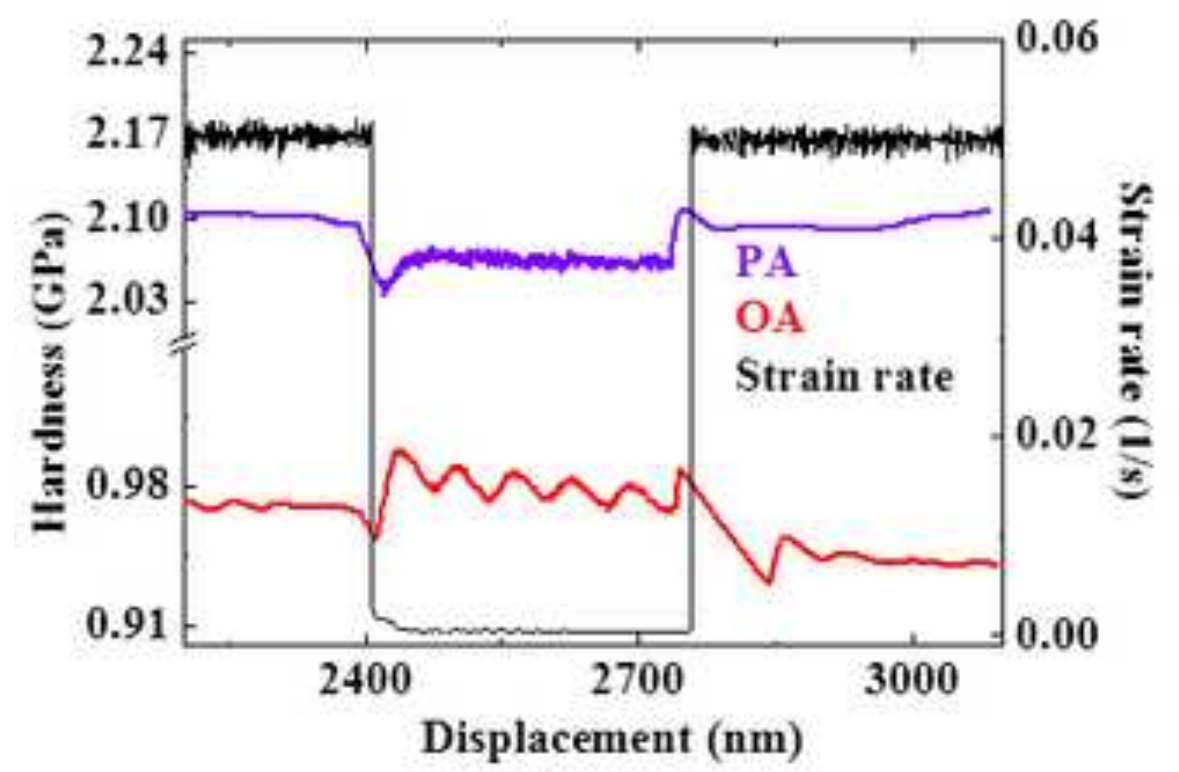

(c)

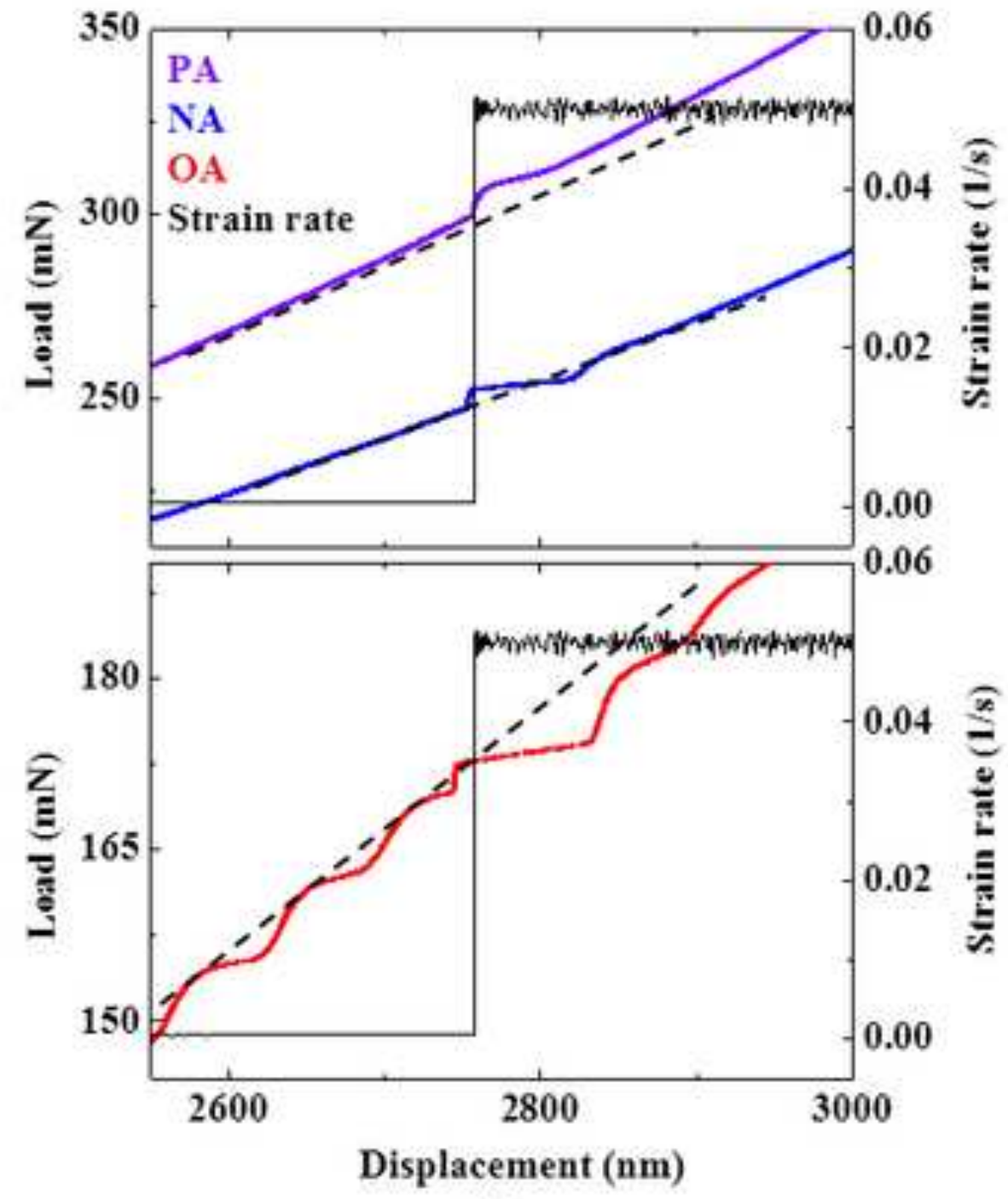

(b) 


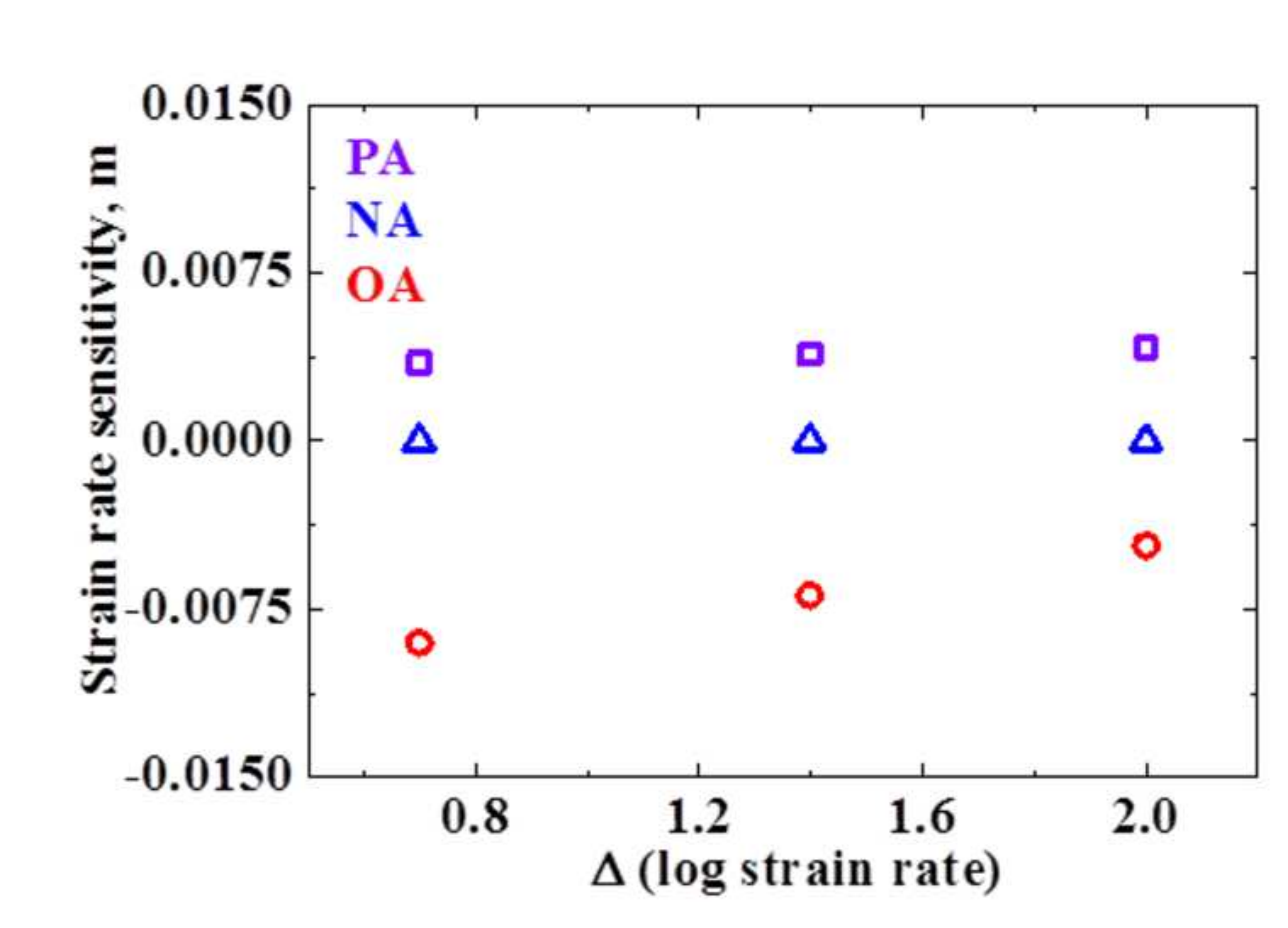

\author{
Fig
}



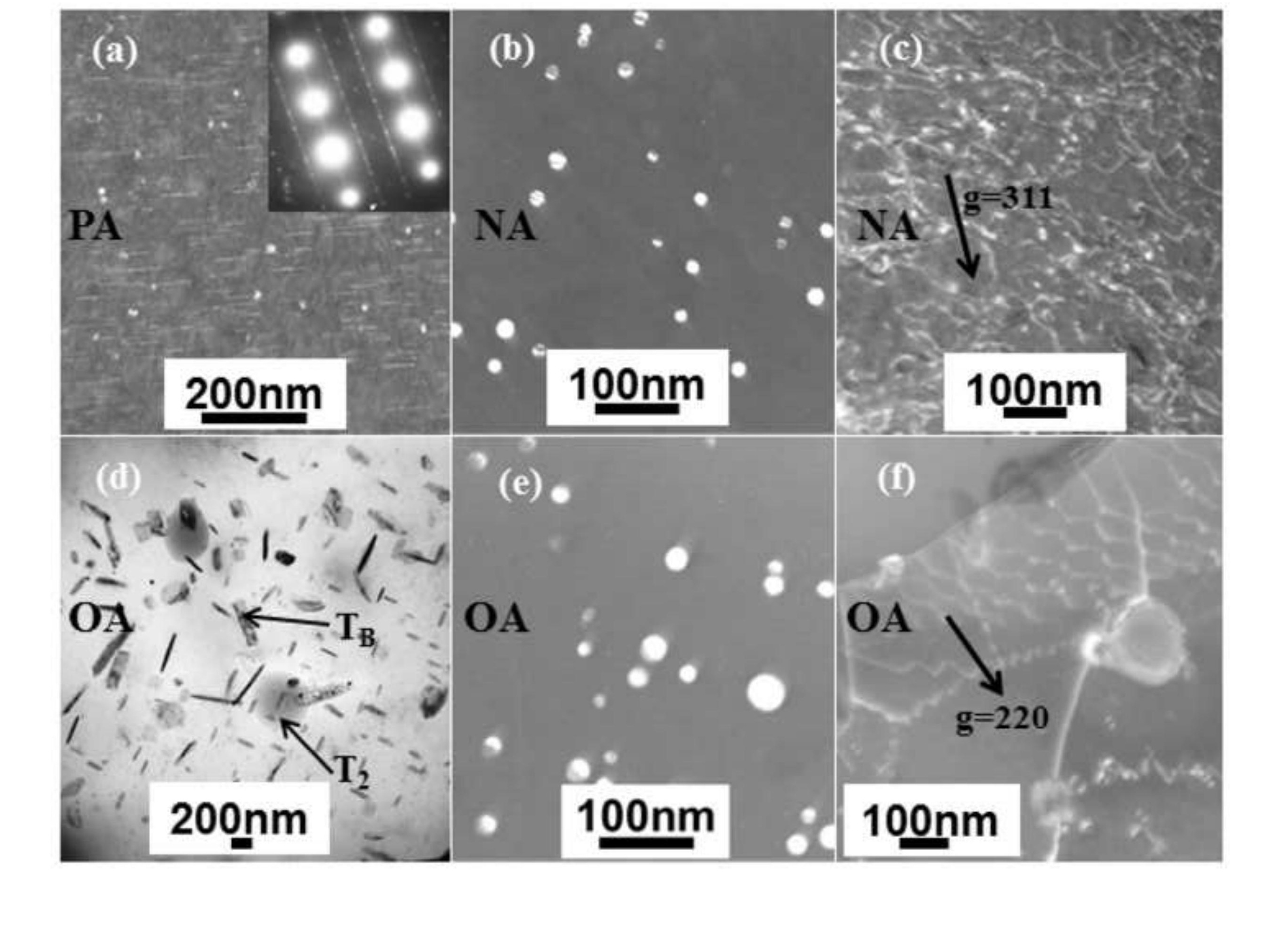


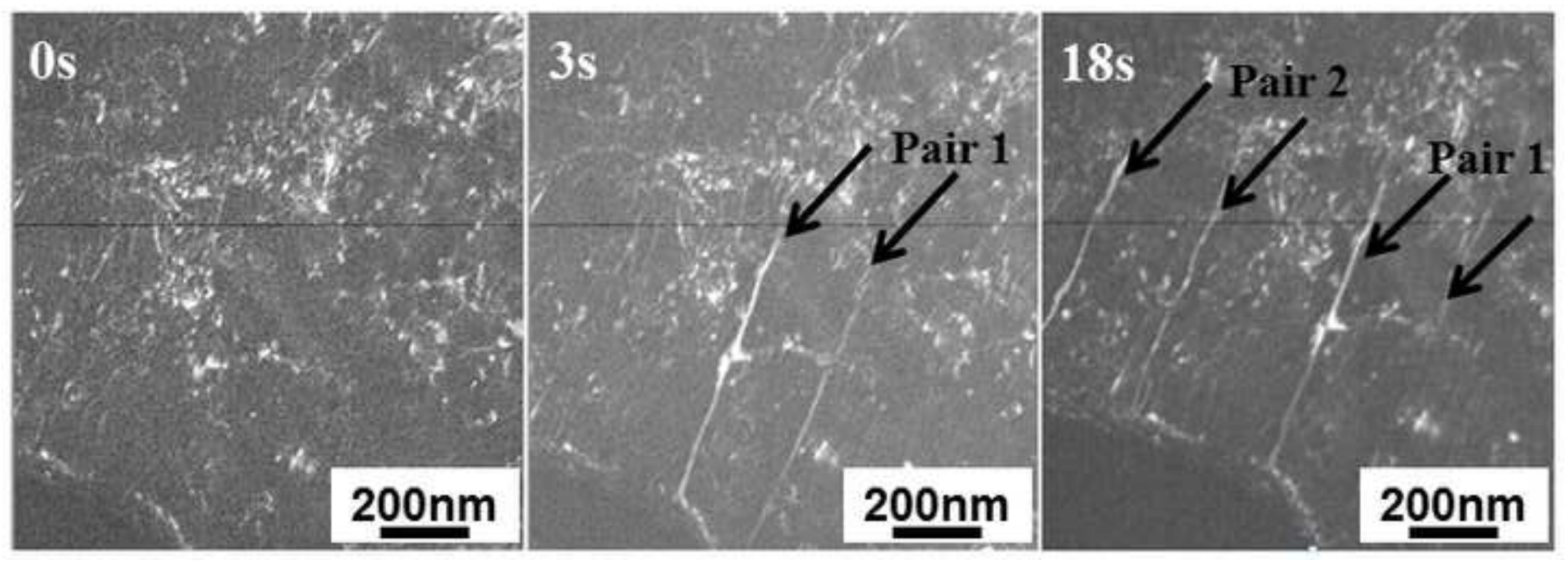




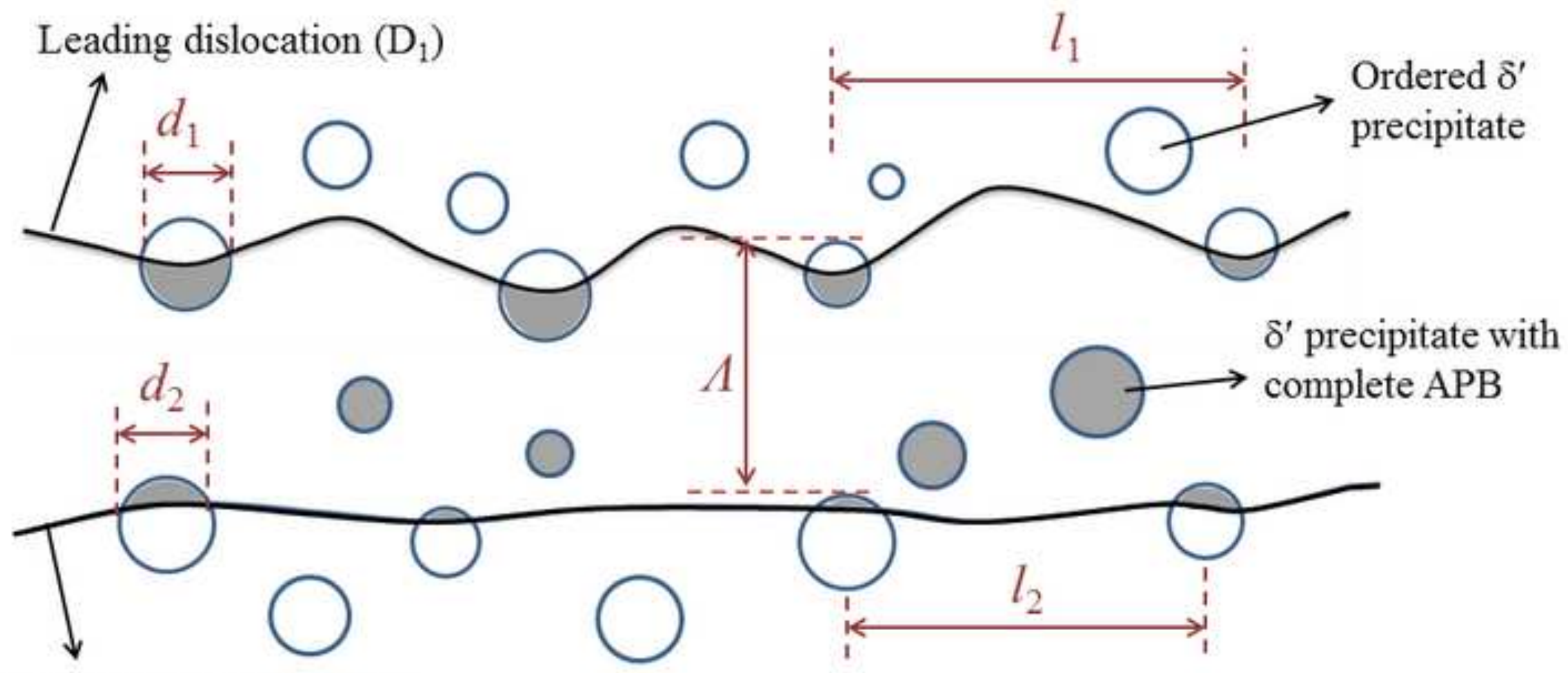

Trailing dislocation $\left(\mathrm{D}_{2}\right)$ 


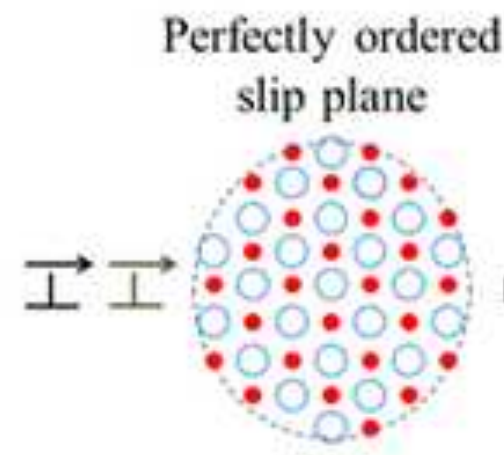

(i)

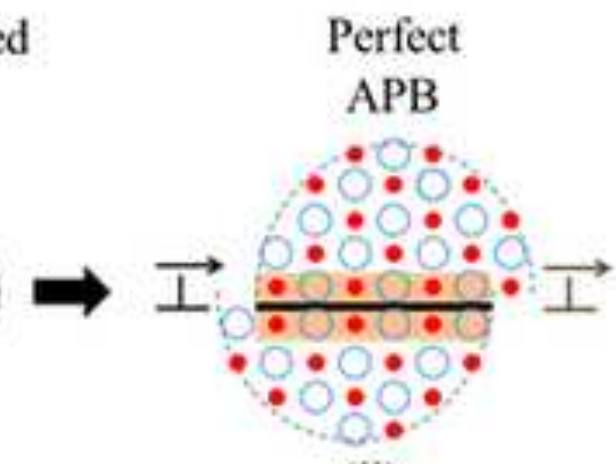

(ii)
Perfectly re-ordered slip plane

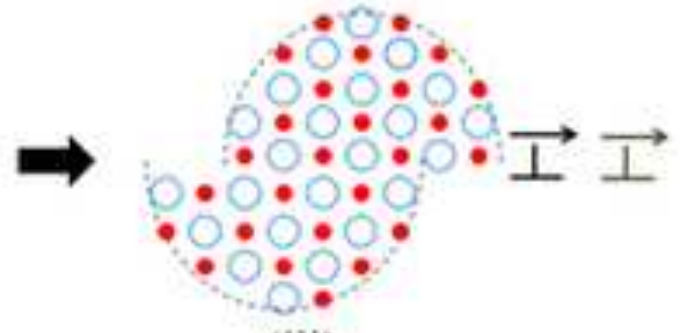

(iii)

(a)

Perfectly ordered slip plane

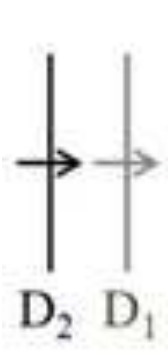

(i)

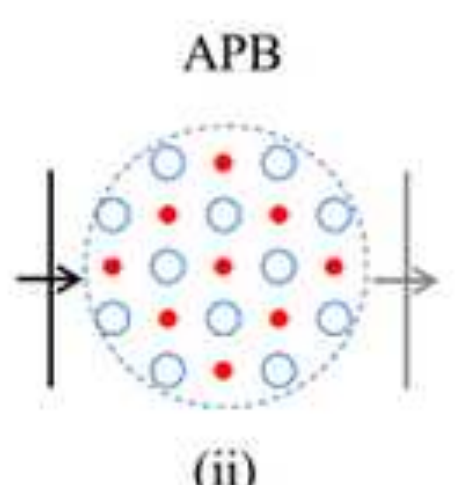

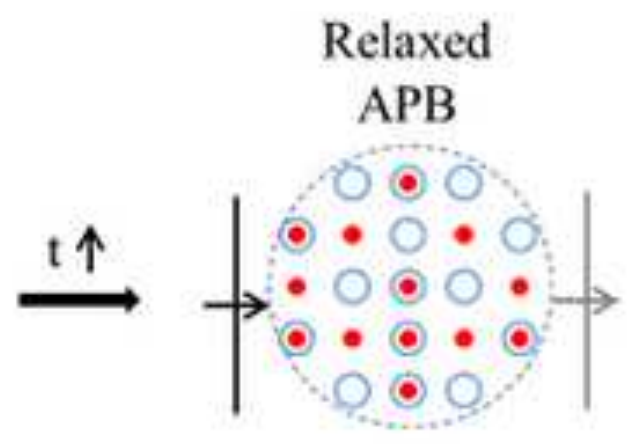

(iii)

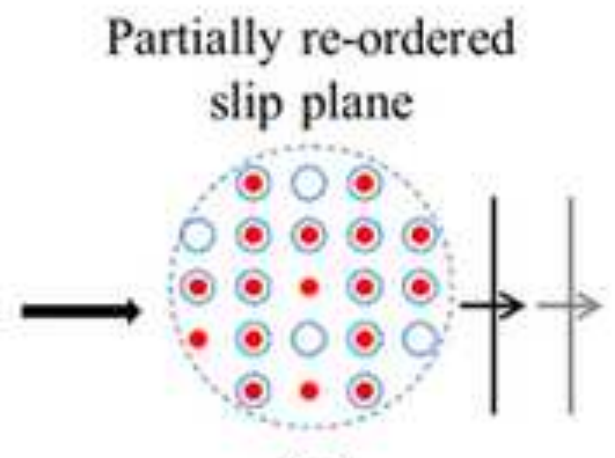

(iv)
Perfectly re-ordered slip plane

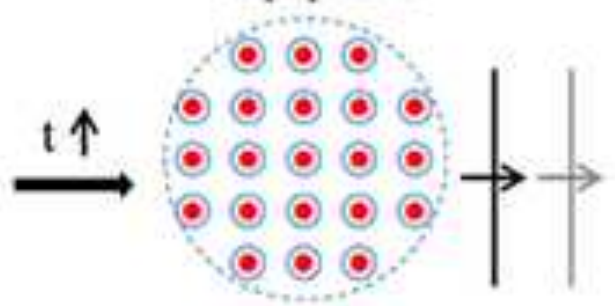

(v)

(b) 